\title{
Review \\ The Japanese Wild-Derived Inbred Mouse Strain, MSM/Ms in Cancer Research
}

\author{
Kazuhiro Okumura, Megumi Saito, Eriko Isogai and Yuichi Wakabayashi *(D) \\ Cancer Genome Center, Division of Experimental Animal Research, Chiba Cancer Center Research Institute, \\ 666-2 Nitonamachi Chuouku, Chiba 260-8717, Japan; kokumura@chiba-cc.jp (K.O.); \\ megumi.s.1634@gmail.com (M.S.); eisogai@chiba-cc.jp (E.I.) \\ * Correspondence: yuichi_wakabayashi@chiba-cc.jp; Tel.: +81-43-264-5431 (ex. 5510); Fax: +81-43-262-8680
}

check for updates

Citation: Okumura, K.; Saito, M.; Isogai, E.; Wakabayashi, Y. The Japanese Wild-Derived Inbred Mouse Strain, MSM/Ms in Cancer Research. Cancers 2021, 13, 1026. https:// doi.org/10.3390/cancers13051026

Academic Editor: Kay-Uwe Wagner

Received: 29 January 2021

Accepted: 25 February 2021

Published: 1 March 2021

Publisher's Note: MDPI stays neutral with regard to jurisdictional claims in published maps and institutional affiliations.

Copyright: (C) 2021 by the authors. Licensee MDPI, Basel, Switzerland. This article is an open access article distributed under the terms and conditions of the Creative Commons Attribution (CC BY) license (https:/ / creativecommons.org/licenses/by/ $4.0 /)$.
Simple Summary: Since human studies on tumor susceptibility alleles require vast numbers of DNA samples from both cancer patients and well-matched controls, their investigation and identification in humans have been complemented using mouse models. However, a number of confounding factors are associated with this type of research, including heterogeneity, weak genetic interactions, and lifestyle habits. Inbred strains relatively recently established from wild mice are often more resistant to carcinogenic stimulation and various pathogens than standard inbred mouse strains. A Japanese wild-derived inbred mouse strain, MSM/Ms has been used to map tumor resistance loci as well as other Quantitative Trait Loci (QTL) in Japan. Furthermore, genetic tools have been developed with MSM/Ms. MSM/Ms genomic sequences are currently available, which have greatly promoted the identification of tumor resistance loci as well as genes controlling quantitative variations and provide a more detailed understanding of gene function.

Abstract: MSM/Ms is a unique inbred mouse strain derived from the Japanese wild mouse, Mus musculus molossinus, which has been approximately 1 million years genetically distant from standard inbred mouse strains mainly derived from M. m. domesticus. Due to its genetic divergence, MSM/Ms has been broadly used in linkage studies. A bacterial artificial chromosome (BAC) library was constructed for the MSM/Ms genome, and sequence analysis of the MSM/Ms genome showed approximately $1 \%$ of nucleotides differed from those in the commonly used inbred mouse strain, C57BL/6J. Therefore, MSM/Ms mice are thought to be useful for functional genome studies. MSM/Ms mice show unique characteristics of phenotypes, including its smaller body size, resistance to high-fat-dietinduced diabetes, high locomotive activity, and resistance to age-onset hearing loss, inflammation, and tumorigenesis, which are distinct from those of common inbred mouse strains. Furthermore, ES (Embryonic Stem) cell lines established from MSM/Ms allow the MSM/Ms genome to be genetically manipulated. Therefore, genomic and phenotypic analyses of MSM/Ms reveal novel insights into gene functions that were previously not obtained from research on common laboratory strains. Tumorigenesis-related MSM/Ms-specific genetic traits have been intensively investigated in Japan. Furthermore, radiation-induced thymic lymphomas and chemically-induced skin tumors have been extensively examined using MSM/Ms.

Keywords: wild-derived inbred mice; Mus musculus molossinus; MSM/Ms; carcinogenesis

\section{Introduction}

Genome-wide association studies (GWAS) of human cancer have been relatively easily performed recently because next-generation sequencing has been conducted worldwide. However, this research requires a huge number of samples from both cancer patients and well-matched controls. As a number of confounding factors are associated with GWAS, such as heterogeneity, weak genetic interactions, and lifestyle habits, a vast number of cases and controls are needed to reach statistically reliable significance [1,2]. Therefore, mouse 
models of cancer are frequently employed to examine the genetic mechanisms conferring cancer susceptibility and resistance. They have contributed to identifying genetic loci that increase the incidence of cancer, some of which function by itself or in combinations [3-8].

Relatively recently, inbred mouse strains established from wild mice were found to often be more resistant to carcinogenic stimulation and various pathogens than standard inbred mouse strains. Mus spretus, a European wild-derived inbred mouse strain, has been shown to exhibit dominant resistance to several cancers [9-11]. M. spretus is resistant to two-stage skin carcinogenesis initiated by the application of dimethylbenz(a)anthracene (DMBA) and promoted by the application of 12-O-tetradecanoylphorbol-13-acetate (TPA). Balmain and colleagues at the University of Glasgow performed a quantitative trait locus (QTL) analysis to map tumor susceptibility/resistance loci on F1 backcross mice using Mus spretus and found 15 skin tumor susceptibility loci, Skts1-15 [9,12]. A previous study reported the presence of the $S k t s 1$ locus in an intercross of several inbred mouse strains, like the collaborative cross recently performed [13]. A number of skin tumor modifier loci besides the Skts series were also identified in standard inbred mouse strains and wild-derived inbred mouse strains. The Ptch gene was previously reported to be a genetic modifier of spontaneous squamous cell carcinoma development induce by Karatin5 (K5) Hras transgene in backcross mice between commonly used inbred mouse strains [14], while Psl1-4 were reported to be modifiers of DMBA/TPA induced skin tumors in backcross mice between commonly used inbred mouse strains [15,16]. Moreover, Skts-fp 1-3 were reported to be modifiers of DMBA/TPA-induced skin tumors in backcross mice using $P W K$ mice which is a wild-derived inbred mouse strain [17]. Skts-fp 1 was detected also in a cross using M. m. castaneous as well [18].

There are currently four subspecies of M. musculus: $M . m$. domesticus, M. m. bactrianus, M. m. musculus, and M. m. castaneus [19]. An additional subspecies, M. m. molossinus has been identified in Japan; however, since SSLP (Simple Sequence Length Polymorphisms) analysis revealed M. m. molossinus was generated by hybridization between M. m. musculus and M. m. castaneus, it is not a novel subspecies [20]. Shiroishi and colleagues at the National Institute of Genetics (Shizuoka, Japan) previously determined the sequences of the two genomes of M. m. molossinus-derived inbred strains, MSM/Ms (MISHIMA/Mishima) and JF1/Ms (Japanese Fancy Mouse 1/Mishima). MSM/Ms was established from Japanese wild mice and the ancestry of JF1/Ms was originally found at the street market in Europe and then brought to Japan because the mouse had black spots on the back and looked similar to the mice which appeared on an old book published in the Edo era [21]. These sequences were compared with the C57BL/6J (C57BLACK/6Jackson) reference sequences and the sequences of 17 inbred strains. The results clearly showed that genome incorporation occurred from M. m. molossinus into M. m. domesticus, which contributed to produce the basic genomic structure of classical inbred mouse strains. Moreover, long segments were found to be shared in the genomes between classical inbred mouse strains including C57BL/6J and JF1/Ms mice.

The MSM/Ms strain was established from M. m. molossinus. The first group of mice was captured in one citizen's house in Mishima, Japan. After several rounds of mating, those mice were donated to Dr. Moriwaki at the National Institute of Genetics (Mishima, Japan) in 1978 [22]. They started sister-brother mating in the institute. Inbreeding has reached generation N100 and, thus, these mice are now recognized as an inbred mouse strain like other commonly inbred mouse strains. Due to its genetic divergence from standard inbred mouse strains mainly established from M. m. domesticus, MSM/Ms has been broadly used in linkage studies mainly in Japan. A bacterial artificial chromosome (BAC) library has been constructed for the MSM/Ms genome, and sequence analysis of the MSM/Ms genome showed approximately $1 \%$ of nucleotide sequences differed from those in the standard inbred mouse strain, C57BL/6J $[23,24]$. Therefore, the MSM/Ms strain has been used for investigations of gene functions including SNPs (Single Nucleotide Polymorphisms). These genomic sequence differences make phenotypes of MSM/Ms mice very different from those of commonly used inbred mouse strains; they have a smaller body 
size [22], resistance to high-fat-diet-induced diabetes [25], high locomotive activity [26], and resistance to age-onset hearing loss [27,28], inflammation [29], and tumorigenesis [22,29-36] (Table 1). Furthermore, ES cell lines established from MSM/Ms enable us to manipulate the MSM/Ms genome [37]. Therefore, genomic and phenotypic analyses of MSM/Ms reveal novel insights into gene function that have not been possible using common laboratory strains.

Table 1. Tumor types examined with MSM/Ms (MISHIMA/Mishima).

\begin{tabular}{ccc}
\hline Tumor Induction & Tumor Types & References \\
\hline Urethan & Lung tumors & {$[22]$} \\
PhIP & Intestinal tumors & {$[29]$} \\
Min mice & Intestinal tumors & {$[30]$} \\
MuLV & B-cell lymphomas & {$[31]$} \\
$\gamma$-ray & Thymic lymphomas & {$[32,33]$} \\
DEN & Hepatocellular carcinomas & {$[34]$} \\
MNU & Forestomach tumors & {$[35]$} \\
DMBA/TPA & Skin tumors & {$[36]$} \\
\hline
\end{tabular}

PhIP; 2-Amino-1-methyl-6-phenylimidazo (4,5-b) pyridine, Min; Multiple intestinal neoplasia, MuLV; Murine leukemia virus, DEN; Diethylnitrosamine, MNU; N-methyl-N-nitrosourea, DMBA; 7. 12-Dimethylbenz(a)anthracene, TPA; 12-O-Tetradecanoylphorbol-13-acetate.

We herein focused on the resistance of MSM/Ms to cancer. As we mentioned earlier, inbred mouse strains recently derived from wild mice are often resistant to carcinogenic stimulation. Mus musculus inbred strains have significantly longer telomeres than mouse strains derived from wild mice [38,39]. It is still necessary to map the stable inheritance of telomeres and to assess the expression of telomerase in the MSM/Ms strain. Since it is a hybrid between M. m. musculus and M. m. castaneus, it may have implications for cancer modeling. Radiation-induced thymic lymphomas and chemically-induced skin tumors have been extensively examined using MSM/Ms. We will mainly review these two types of tumor studies using MSM/Ms.

\section{Radiation-Induced Thymic Lymphomas}

\subsection{Identification of Tumor Resistance Loci}

Resistance to radiation-induced thymic lymphomas is dependent on mouse strains $[40,41]$ (Table 2). BALB/c (Bagg ALBINO/c genotype at the color locus) is a susceptible strain to the radiation-induced mouse thymic lymphomagenesis, whereas MSM/Ms is resistant. The incidence of radiation-induced thymic lymphomas in F1 mice is similar to that in $\mathrm{BALB} / \mathrm{c}$, indicating that BALB/c exhibits dominant susceptibility to these lymphomas. Kominami and colleagues at Niigata University (Niigata, Japan) examined an association with the control of lymphoma susceptibility of backcross mice between these two strains to identify the genetic loci involved [33]. Three markers, D2Mit15 (Thyls1 for Thymic lymphoma susceptibility 1), D4Mit12 (Thyls2), and D5Mit5 (Thyls3), showed a strong linkage (Figure 1). Mice having lymphoma exhibited more heterozygous genotypes at D2Mit15 and D4Mit12 than MSM/Ms homozygosity, indicating that BALB/c has a dominant susceptible allele in these loci, whereas MSM/Ms has resistant alleles. However, the genotype of mice with lymphoma exhibited more MSM/Ms homozygosity than heterozygosity at D5Mit5, indicating MSM/Ms has susceptible alleles in this locus. Cooperative effects on lymphomagenesis were also observed among the three loci.

In an attempt to cut down the candidate interval around D4Mit12, congenic mice carrying a 40-Mb chromosomal region on chromosome 4 from the MSM/Ms genome were generated. These mice were crossed with BALB/c mice to further divide the congenic region. As a result, four subcongenic lines were generated by genotyping with microsatellite markers [42]. Congenic mapping and a haplotype analysis suggested metal-responsive transcription factor-1 (Mtf-1) was a responsible gene for Thyls2 on chromosome 4 . Sequence analysis showed lymphoma susceptible strains had a polymorphism in $M t f-1$, in which 
serine exists at position 424 in the proline-rich domain. In contrast, lymphoma-resistant strains were found to have proline in that position. Comparisons of the transcriptional activity of $M t f-1$ having both alleles were performed by expressing both constructs in $M t f-$ 1-deficient cells, respectively. As a result, proline at position 424 conferred stronger metal responsiveness. The radiation inducibility of target genes was also stronger in resistant congenic lines having the $M t f-1$ allele of the proline type. As the target products induced by irradiation inhibited the cellular stresses, resistant congenic strains to thymic lymphomas having the proline type seemed resistant to radiation effects, which probably resulted in resistance to the development of lymphoma.

Table 2. Tumor resistance is dependent on mouse strains.

\begin{tabular}{ccccc}
\hline Tumor Types & FVB/N & BALB/c & C57BL6/J & MSM/Ms \\
\hline $\begin{array}{c}\text { Resistance to radiation-induced } \\
\text { lymphomas }\end{array}$ & ++ & ++ & +++ & +++++ \\
$\begin{array}{l}\text { Resistance to chemically- } \\
\text { induced skin tumors }\end{array}$ & + & ++ & +++ & +++++ \\
\hline
\end{tabular}

+ indicates the extent of tumor resistance. The more + means the more resistant.

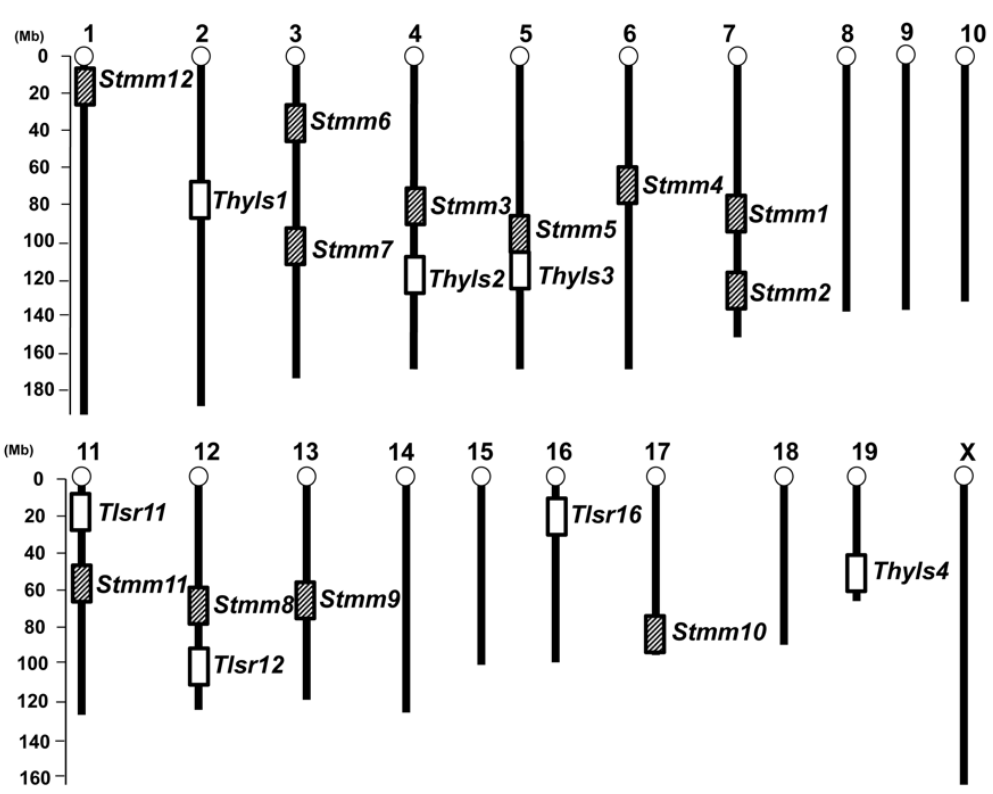

Figure 1. Tumor resistance (susceptibility) and LOH (Loss of Heterozygosity) regions identified in skin and radiationinduced tumors with MSM. Stmm; Skin tumor modifier of MSM, Thyls; Thymic lymphoma susceptibility, Tlsr; Thymic lymphoma suppressor region. Shaded squares indicate Stmm loci identified in skin. White squares indicate Thyls and Tlsr loci identified in thymic lymphomas. Black bars indicate each chromosome.

Kominami and colleagues generated congenic mouse lines covering a $28.4 \mathrm{cM}$ interval of Thyls3 on chromosome 5 by eliminating genomic DNA of susceptible MSM/Ms alleles from F1 mice between BALB/c and MSM/Ms mice to confirm the susceptibility genes in the Thyls3 region of MSM/Ms. MSM/Ms itself is a strain resistant to thymic lymphomagenesis. However, the Thyls3 locus on chromosome 5 of MSM/Ms exceptionally conferred susceptibility to lymphomas [43]. They induced lymphomas in these congenic mice in two ways. Half of the congenic mice were subjected to irradiation, and the other half of the mice were administered $N$-methyl- $N$-nitrosourea (MNU), an alkylating agent. As a result, $87.5 \%$ of the irradiated congenic mice that are MSM/Ms homozygous at D5Mit5 developed radiogenic lymphomas. On the other hand, $46 \%$ of the irradiated congenic mice that are heterozygous at D5Mit5 developed radiogenic lymphomas. MSM/Ms homozygosity at D5Mit5 gave rise to a significantly higher frequency of radiogenic lymphomas. These results strongly suggested MSM/Ms had a strong susceptible allele in Thyls3 on 
chromosome 5. In contrast, the difference in the frequencies of MNU-induced thymic lymphomas was not detected between MSM/Ms homozygosity and heterozygosity at D5Mit5. These findings indicated a susceptible MSM/Ms allele for thymic lymphomas and Thyls3 conferred susceptibility specifically to radiation carcinogenesis, but not to MNU.

In order to identify p53 (Trp53)-dependent tumor resistance genes, Kominami and colleagues also attempted to map genetic modifiers of radiation-induced thymic lymphomas and skin tumors in $p 53$ knockout MSM/Ms mice [44]. $p 53^{+/-}$backcross mice were generated by crossing $p 53$ knockout MSM/Ms mice with FVB/N mice and were subjected to radiation to induce a large number of lymphomas and skin tumors. Genome-wide screening exhibited BALB/c alleles at D19Mit5, D19Mit90, and D19Mit123 on chromosome 19 prolonged the latency of the development of thymic lymphoma and the survival of the mice (Thyls4, Figure 1). These results indicated that BALB/c alleles in the Thyls4 region conferred resistance to radiation-induced thymic lymphomas and MSM alleles in that region conferred susceptibility on $p 53^{+/-}$background. This is the same situation as shown in Thyls3 on chromosome 5, as mentioned earlier. D19Mit90 and D19Mit123 also showed the linkage to the latency of skin tumors and survival, whereas D19Mit5 did not show the linkage. In order to confirm the linkage at the three markers to the development of thymic lymphomas, they crossed $p 53^{+/-}$BALB/c mice with consomic mice having chromosome 19 of MSM/Ms on the BALB/c background. These mice were subjected to radiation and the linkage study was carried out. As a result, D19Mit90 exhibited a significant linkage as well as in the backcross study. In contrast, D19Mit5 and D19Mit123 did not show any linkage. These results suggest two possibilities. Consomic mice were originally generated on the C57BL6/J background and backcrossed to BALB/c mice several times to replace the background strain. The C57BL6/J genome could remain and mask the effect of MSM/Ms alleles of D19Mit5 and D19Mit123. The second is that the linkage at D19Mit5 and D19Mit123 were dependent on epistatic interactions. In other words, the D19Mit90 region could function by itself, whereas the D19Mit5 and D19Mit123 regions could require other regions from $\mathrm{MSM} / \mathrm{Ms}$ to work in combinations.

\subsection{Genetic Analysis of the LOH Region}

Kominami and colleagues performed a genome-wide $\mathrm{LOH}$ analysis of radiationinduced thymic lymphomas obtained from F1 mice between BALB/c and MSM/Ms mice and backcross mice that are heterozygous for several chromosomes. Approximately 50\% of those mice were a $p 53^{+/-}$[45]. The findings obtained revealed that two loci exhibited frequent $\mathrm{LOH}$ and both alleles of the two loci were equally lost; one was mapped within a $2.9 \mathrm{cM}$ region (Tlsr12 for Thymic lymphoma suppressor 12) between D12Mit53 and D12Mit279, and the other was mapped near D16Mit122/D16Mit162 (Tlsr16) (Figure 1). D12Mit279 showed $62 \%$ of LOH frequency, regardless of the presence of the $p 53^{+/}-$allele. In contrast, D16Mit122 showed $62 \%$ of LOH frequency on the $p 53^{+/-}$background and $13 \%$ on the $p 53^{+/+}$background, suggesting the presence of $p 53^{+/-}$allele increased the frequency of LOH at D16Mit122. These results strongly suggested at least two types of tumor suppressor genes were located around D12Mit279 and D16Mit122, one was independent of $p 53$ and the other was dependent on $p 53$.

They generated a physical map encompassing the Tlsr12 locus with YAC and BAC clones to isolate new probes and to further narrow down the candidate interval having suspected tumor suppressor genes [46]. Allelic loss mapping with polymorphic markers from YAC and BAC clones finally revealed both alleles of two end markers of one BAC clone were retained, and one marker between the two end markers showed $\mathrm{LOH}$ in genomic DNA of lymphoma tissues, strongly suggesting the minimal interval of $\mathrm{LOH}$ on chromosome 12 was covered by the BAC clone.

Sequence analysis of the peak $\mathrm{LOH}$ region was then conducted. The findings obtained showed the isolation of the $B c l 11 b$ gene from this region [47]. Biallelic changes were more frequently detected in $p 53$-proficient lymphomas than in p53-deficient lymphomas, indicating inactivation of the $B c l 11 b$ gene is dependent on the presence of functional $p 53$ 
in the development of lymphoma. The introduction of $B c l 11 b$ into cultured tumor cell lines lacking the expression of $B c l 11 b$ exhibited a suppressive effect of $B c l 11 b$ on tumor cell growth. Taken together, these findings suggested that biallelic mutations in $B c l 11 b$ contributed to mouse lymphomagenesis on a $p 53$ wild-type background.

$B c l 11 b$-deficient mice were then generated by a conventional gene targeting method, in which homologous recombinant ES cells were selected in the presence of neomycin. Bcl11bdeficient mice exhibited neonatal death. A significant block in thymocyte differentiation at the $\mathrm{CD}^{-} \mathrm{CD}^{-}$the double-negative stage was observed in the neonatal thymus of these knockout mice. In contrast, any impairment was not observed in cells of the B or $\gamma \delta \mathrm{T}$ cell lineage in thymocyte development [48]. In addition, the unsuccessful recombination of $\mathrm{V}(\beta)$ to $\mathrm{D}(\beta)$ was seen in $B c l 11 b^{-/-}$thymocytes, which also lacked the pre-T cell receptor (TCR) complex due to the lack of Tcrb mRNA. Furthermore, markedly increased apoptosis was observed in the neonatal thymus of $\mathrm{Bcll}_{1} \mathrm{~b}^{-/-}$mice. These findings suggested that $B c l 11 b$ is essential for both differentiation and survival in the development of thymocytes.

$B c 111 b$-deficient mice were mated with $p 53$-deficient mice and subjected to radiation. $B c l 11 b^{+/-} p 53^{+/-}$mice subsequently developed significantly more lymphomas than $B c l 11 b^{+/+} p 53^{+/-}$mice; however, the wild-type $B c l 11 b$ allele was retained and expressed in the majority of lymphomas [49]. These findings suggested that Bcl11b was haploinsufficient for the suppression of thymic lymphomagenesis in $p 53^{+/-}$mice, namely a condition under which the functional loss of only one allele was enough to confer an advantage for tumorigenesis. Furthermore, haploinsufficiency was supported by the findings that impairment in thymocyte development and survival was seen in $B c l 11 b^{+/-}$mouse embryos as well as in $B c l 11 b^{-/-}$mice.

Their genome-wide analysis of allelic loss for radiation-induced thymic lymphomas revealed the $\mathrm{LOH}$ region (Tlsr11, Figure 1) on the top of chromosome 11 in addition to chromosomes 12 and 16, as mentioned earlier. As mouse genome information was accumulated at that moment, the Ikaros gene was identified in this region from the database [50]. Fine allelic loss mapping around the Ikaros gene in genomic DNA of lymphomas suggested that the critical region of allelic loss was found in the middle of the Ikaros gene. The Nterminal zinc finger and the activation domains of Ikaros exhibited homozygous deletions and mutations. These findings strongly indicated Ikaros plays a key role in mouse thymic lymphomagenesis. Since the Ikaros gene showed biallelic changes at a high frequency in radiation-induced mouse thymic lymphomas, they investigated two other members of the Ikaros gene family, Helios on chromosome 1 and Aiolos on chromosome 11, [51]. Genetic analysis with adjacent MIT markers to the two genes suggested neither locus showed LOH in genomic DNA of the thymic lymphomas on the p53 wild-type background. In contrast, both Helios and Aiolos loci showed LOH on the $p 53$ heterozygous background. These results suggested tumor-suppressive functions of Helios and Aiolos were dependent on p53 loss.

\section{Chemically-Induced Skin Tumors}

\subsection{Identification of Tumor Resistance Loci}

Resistance to chemically-induced skin tumors is highly dependent on mouse strains [52] (Table 2). We previously reported that MSM/Ms is a dominant resistant strain to chemicallyinduced skin tumors when they are crossed with a highly susceptible strain, FVB/N (Friend Virus B/NIH), and treated with DMBA/TPA according to the standard two-stage skin carcinogenesis protocol [36]. In order to carry out genome-wide screening of genetic modifiers for DMBA/TPA-induced skin tumors, we generated $p 53^{+/-}$or $p 53^{+/+}$backcross mice between FVB/N and MSM/Ms mice. Approximately 50\% of these backcross mice were $p 53^{+/-}$, which allowed us to screen $p 53$-dependent skin tumor modifier loci as well as $p 53$-non-dependent modifier loci. Genome-wide genetic modifier screening showed a significant linkage to the number of papillomas on chromosomes 6 (Stmm4 for Skin tumor modifier of MSM/Ms) and 7 (Stmm1,2) and a possible linkage on chromosomes 1 (Stmm12), 3 (Stmm6, 7), 5 (Stmm5), 11 (Stmm11), 12 (Stmm8), 13 (Stmm9), and 17 (Stmm10) (Figure 1). We then classified tumors into three size categories (<2 (hereafter "micro"), 2-6 (hereafter 
"middle"), and $>6 \mathrm{~mm}$ (hereafter "large")) and performed linkage analysis to identify stage-dependent linkage loci. The Skts1 locus on chromosome 7 showed a strong linkage in mice that developed micro or middle-sized papillomas. However, we did not see any linkage on chromosome 7 in mice that developed large papillomas, whereas a linkage to large papillomas and carcinomas was seen at a different locus on the chromosome (Stmm3, Figure 1). Stmm 3 locus, which was detected around the $C d k n 2 a / \mathrm{p} 19^{\text {Arf }}$ gene showed $p 53-$ dependency because this locus was detected only in $p 53^{+/+}$backcross mice, not detected in $p 53^{+/-}$backcross mice. Furthermore, a suggestive linkage conferring "susceptibility" to carcinoma was also found on chromosome 5 (Stmm5). This is the only "susceptibility" locus MSM/Ms conferred in our study, although MSM/Ms itself is very resistant. These findings strongly suggested that multiple loci regulate each stage of tumorigenesis, some of them showed $p 53$ dependency.

\subsection{Tumor Resistance Loci on Chromosome 7}

To confirm the presence of tumor resistance loci on chromosome 7 , we selected resistant backcross mice and eliminated MSM/Ms genomic DNA by backcrossing the mice to $\mathrm{FVB} / \mathrm{N}$ mice in order to generate congenic mouse lines spanning the linkage region on chromosome 7 [53]. We first generated congenic mouse lines covering the Stmm1 and Stmm2 regions, respectively. Successive rounds of crossing and repeated DMBA/TPA chemical carcinogenesis experiments on each line allowed us to eliminate the whole Stmm2 region from the candidate interval and to cut down the Stmm 1 region to approximately $3 \mathrm{cM}$ regions.

We then checked allelic imbalances on chromosome 7 to investigate the specific location of somatic changes in the Stmm1 region on chromosome 7. Two allelic imbalance peaks were observed within the $3 \mathrm{cM}$ region identified with the multiple congenic lines covering the Stmm 1 region. The combination of these two peak regions reduced the total physical size of the Stmm1 region to approximately $5.4 \mathrm{Mb}$ [53].

We continued congenic mapping and DMBA/TPA chemical carcinogenesis and narrowed down the candidate interval of Stmm 1 to a region of $3.4 \mathrm{Mb}$ on chromosome 7. Pth (parathyroid hormone) was detected among the genes mapped within the Stmm1 region [54]. PTH is well-known to function cooperatively with vitamin D to regulate calcium and phosphate homeostasis in the blood. However, the role of PTH in skin tumorigenesis has not yet been elucidated in detail. Previous studies reported that PTH slowed down the proliferation and differentiation of cells in the epidermis, suggesting its role in skin tumorigenesis [55]. We first measured the concentration of intact PTH (iPTH) in sera of cancer-resistant MSM/MS and susceptible FVB mice. As a result, significantly higher iPTH level was detected in sera from MSM/Ms than from FVB/NJ mice. Therefore, skin carcinogenesis experiments were carried out with MSM-BAC transgenic ( $\left.P t h^{\mathrm{MSM}}-\mathrm{Tg}\right)$ and Pth knockout heterozygous mice $\left(P t h^{+/-}\right)$. $P t h^{\mathrm{MSM}}-\mathrm{Tg}$ mice developed a significantly lower number of tumors compared to the wild-type mice. In contrast, $P t h^{+/-}$mice developed a significantly higher number of tumors. These results strongly suggested iPTH in sera regulated skin tumorigenesis in a dose-dependent manner. Moreover, differentiation markers, such as Loricrine and Keratine 10 were highly expressed in the epidermis of $P t h^{\mathrm{MSM}}-T g$, suggesting PTH promoted differentiation of cells in the epidermis. Furthermore, the in vitro experiments showed the coding SNP (rs51104087, Val28Met) in the mouse Pro-PTH encoding region enhanced its processing and secretion of PTH as well as intracellular calcium levels. Collectively, these findings demonstrated that PTH promotes terminal differentiation in keratinocytes by increasing intracellular calcium levels in keratinocytes, which results in resistance to tumors (Figure 2). 


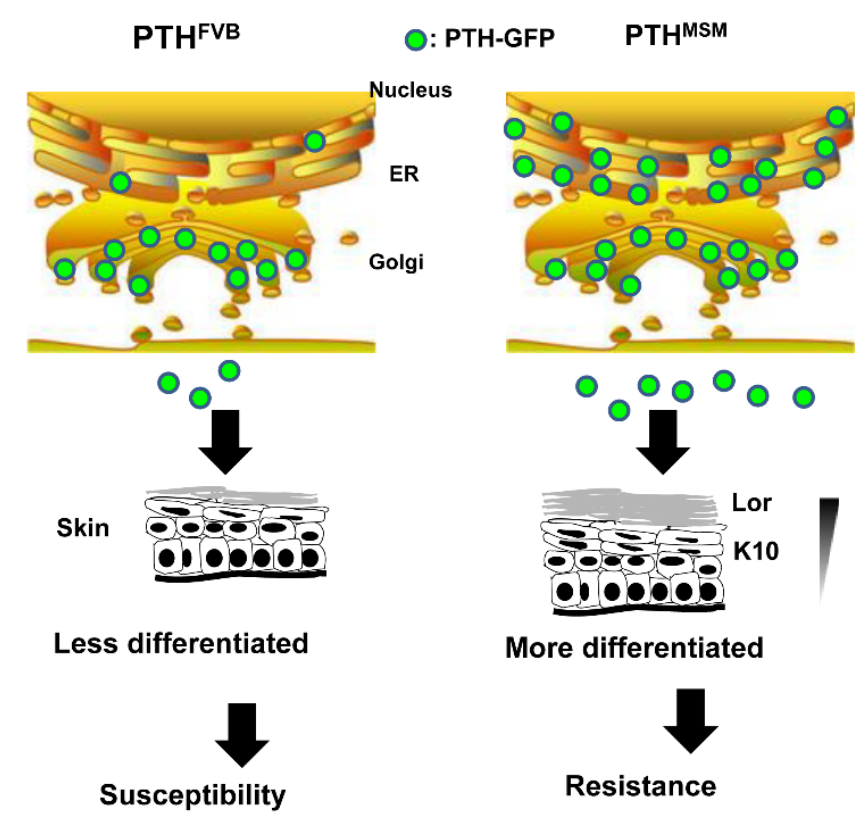

Figure 2. Mechanism of action of PTH in skin tumor resistance. The coding SNP in the Pro-PTH encoding region markedly enhanced the processing and increased secretion of PTH in MSM/Ms. Higher PTH levels elevated calcium levels in keratinocytes, which promoted their differentiation and ultimately led to resistance to skin tumorigenesis. ER denotes Endoplasmic Reticulum. K10 denotes Keratin 10. Lor denotes Loricrin.

Stmm1 region on chromosome 7 was finally subdivided into Stmm1a (about $0.24 \mathrm{Mb}$ ) and Stmm1b (about $4.7 \mathrm{Mb}$ ). Both congenic lines including Stmm1a and Stmm1b exhibited a strong suppressive effect on papilloma development, respectively. Pth was identified in the Stmm1b region. Pak1 (serine/threonine p21-activated kinases 1) was identified in Stmm1a region [56]. It is well-known to exhibit oncogenic activity in several cancers. Therefore, Pak1 knockout mice were generated using ES cells from MSM/Ms with the CRISPR/Cas9 system, and DMBA/TPA skin carcinogenesis experiments were performed using Pak1 ${ }^{+/-}$ $\mathrm{F}_{1}(\mathrm{FVB} / \mathrm{N} \times \mathrm{MSM} / \mathrm{Ms})$ mice. As a result, $\mathrm{Pak1}^{+/-}$mice developed almost no tumor. Immunohistochemistry revealed that PAK1 was strongly expressed in Langerhans cells (LCs) as well as in keratinocytes. Furthermore, Pak1 homozygous knockout mice on MSM/Ms background ( $\left.P a k 1^{-1-} \mathrm{MSM} / \mathrm{Ms}^{-}\right)$showed a significant decrease in the number of LCs. $\mathrm{F}_{1}-\mathrm{Pak1} \mathrm{1}^{+/-}$mice exhibited a decrease in the number of epidermal stem cells in the skin bulge and an increase in the number of Th17 cells in the skin. We generated Pak1 knockdown cells using LC-derived XS52 cells (XS52-Pak1KD) and carried out co-culture experiments with keratinocyte-derived C5N cells. As a result, the proliferation of C5N cells was significantly enhanced in the presence of supernatants of XS52-Pak1KD cells. Taken together, these findings indicated that Pak1 was required for the maintenance of epidermal stem cells, which showed an abnormal growth in the absence of Pak1 in LCs and were not maintained correctly, resulting in the resistance to tumors (Figure 3).

\subsection{Tumor Resistance Loci on Chromosome 4}

In our previous genome-wide linkage study to map genetic modifiers conferring resistance to DMBA/TPA-induced skin tumors, Stmm3 was found to possess loci that conferred strong resistance to larger papillomas on chromosome 4 . To confirm the presence of the tumor resistance loci identified in this region on chromosome 4, we generated congenic mice harboring this region of the MSM genome on the FVB/N background [57]. DMBA-TPA carcinogenesis experiments on each line cut down physical interval to less than $34 \mathrm{Mb}$ on proximal chromosome 4 . We also examined somatic changes in the tumors of congenic mice to further cut down the interval. As a result, allelic imbalances, high frequencies of MSM allele loss, or FVB allele gain were detected, suggesting that a physical distance was cut down to approximately $25 \mathrm{Mb}$. 


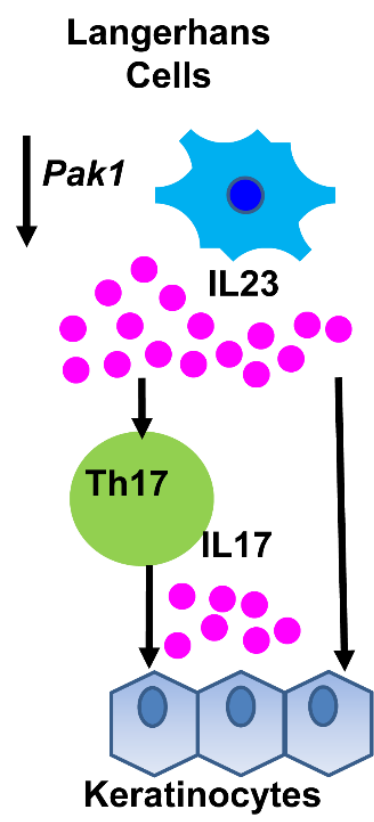

Figure 3. Mechanism of action of PAK in tumor resistance. PAK1 mainly localizes to Langerhans cells (LCs). IL-23 and Th 17 cell numbers were elevated in the skin of $\mathrm{F}_{1}-\mathrm{Pak1} 1^{+/-}$mice. $\mathrm{F}_{1}-\mathrm{Pak} 1^{+/-}$mice had a lower number of epidermal stem cells in the skin bulge, which may be due to the abnormal proliferation of keratinocytes, resulting in tumor resistance.

A congenic line with the minimal interval was crossed with $p 53^{+/-}$FVB mice and these mice were treated with DMBA/TPA. The findings obtained revealed strong inhibitory effects on the development of papilloma in $p 53^{+/+}$congenic mice. In contrast, papilloma development was not markedly suppressed in $p 53^{+/-}$congenic mice. Therefore, the candidate gene was expected to be functionally dependent on $p 53$, which was consistent with our previous findings by the initial linkage analysis of backcross mice [36]. Cdkn2a, a cyclin-dependent kinase inhibitor gene, was detected in the minimal interval. Two different proteins, $\mathrm{p} 16^{\text {Ink4a }}$ and $\mathrm{p} 19^{\text {Arf }}$ are encoded by this locus. These two proteins share exons and are produced from alternative splicing. These two well-known tumor suppressors, $p 16^{\text {Ink } k a}$ and $p 19^{A r f}$ were previously shown to promote the growth-inhibitory effect of pRb and p53 protein, respectively. In addition, the stimulation of separate promoters in the upstream of exon $1 \alpha$ (encoding $p 16^{\text {Ink } 4 a}$ ) and exon $1 \beta$ (encoding $p 19^{A r f}$ ) initiated $R B$ - and $p 53$-dependent programs, respectively $[58,59]$. As our initial linkage and the congenic study suggested the gene responsible Stmm 3 was functionally dependent on $p 53, p 19^{A r f}$ seemed more likely to be responsible for Stmm 3 than $p 16^{\text {Ink4a }}$. To prove $p 19^{\text {Arf }}$ is responsible for Stmm3 and exclude the possibility that $p 19^{A r f}$ is responsible, we eliminated MSM/Ms alleles of $p 16^{\text {Ink4a }}$ and $p 19^{A r f}$ respectively in MSM/Ms ES cell lines with CRISPR/Cas9 system and generated $p 16^{\text {Ink4a }}$ and $p 19^{A r f}$ knockout mice on the MSM/Ms background. These mice were crossed with FVB/N mice to generate $p 16^{\text {Ink4aFVB } /-}\left(p 16^{\text {Ink } 4 a M S M}\right.$ allele knockout $\left.\mathrm{F}_{1}\right)$ and $p 19^{A r f F V B} /-$ ( $p 19^{A r f M S M}$ allele knockout $\mathrm{F}_{1}$ ) mice. They were treated with DMBA/TPA. As a result, a significantly higher number of papillomas developed in $p 19^{A r f F V B /-}$ mice. In contrast, the number of papillomas that developed in $p 16^{\operatorname{Ink} 4 a F V B /-}$ mice did not markedly increase. Therefore, the $p 19^{A r f M S M}$ allele appeared to confer greater resistance to the development of papilloma than the $p 16^{\operatorname{Ink} 4 a M S M}$ allele [60], which indicated that $p 19^{A r f}$ was more likely to be the responsible gene for Stmm3 than $p 16^{I n k 4 a}$. We then separately knocked out the MSM/M allele of $p 19^{A r f}\left(p 19^{A r f M S M}\right)$ and FVB/N allele of $p 19^{A r f}\left(p 19^{A r f F V B}\right)$ on $(\mathrm{FVB} / \mathrm{N} \times \mathrm{MSM} /) \mathrm{F}_{1}$ background and subjected these mice to DMBA/TPA skin carcinogenesis. The numbers of total papillomas and larger papillomas were significantly higher in MSM/Ms allele knockout mice $\left(p 19^{A r f F V B /-}\right)$. These results indicated MSM/Ms allele of $p 19^{A r f}$ more strongly inhibited papilloma genesis and growth than the FVB/N allele, confirming MSM/Ms allele was a resistance gene. We also showed that the p53 pathway was more efficiently activated by the $p 19^{A r f M S M}$ allele than by the $p 19^{A r f F V B}$ allele in vitro (Figure 4). Furthermore, novel 
polymorphisms in human $C D K N 2 A$ that were near the SNP in mouse $C d k n 2 a$ were shown to be associated with the risk of human breast cancers. These results strongly suggested that linkage study started with MSM/Ms mice allowed us to identify the responsible gene for Stmm3 locus, and finally proved its human orthologue functioned as a tumor resistance/susceptibility gene also in humans.

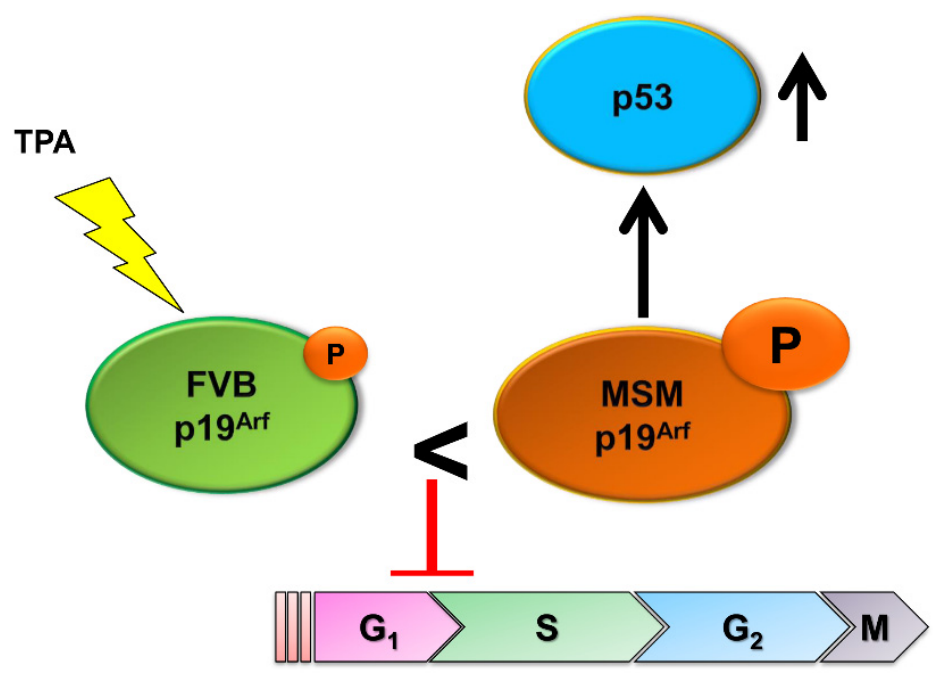

Figure 4. Mechanism of action of MSMp19Arf in tumor resistance. The protein level of MSMp19Arf is higher than that of FVBp19Arf in the presence of TPA. The greater amount of p19Arf more efficiently up-regulates p53 and downstream tumor suppressor genes, resulting in tumor resistance.

\section{Closing Remarks}

MSM/Ms mice were originally captured in Mishima, Japan in the 1970s. After longterm repeated sister-brother mating, the mice were established as a pure inbred mouse strain and have been utilized as a valuable genetic tool for mouse genetics for the past 40 years, mainly in Japan. MSM/Ms mice were originally used mainly for genetic mapping by SSLP markers because of their extensive polymorphism with standard inbred mouse strains. In the field of cancer biology, tumor cell lines were often established from F1 mice between MSM/Ms and inbred mice and used for LOH analysis. As SSLP markers were established, they were used for positional cloning of single trait mutants as well as multigenic traits, including cancer. In this review, we focused on radiation-induced lymphomas and chemically-induced skin tumors. A lot of other cancers and multigenic diseases were examined with MSM/Ms. However, a very limited number of studies reached particular responsible genes. In the majority of studies, genetic loci were mapped on chromosomes, but particular genes were not identified, because of the lack of genome information previously. In other words, a large number of interesting genes are still yet to be identified in MSM/Ms. Genetic resources are already established with MSM/Ms, such as the complete genome sequence information [21], a full set of mouse consomic strains [61], the BAC clone library [24], Microsatellite database [23], and ES cells [37]. Using currently available genetic tools developed from MSM/Ms will allow us to identify responsible genes and polymorphisms for complex traits including cancer, which were previously difficult to handle.

\section{Conclusions}

Recently, new carcinogenesis models, such as organoids, were developed and nextgeneration sequencing of human samples was widely carried out. However, the benefit of mouse models is that all the experiments can be carried out in a situation where the immune system and the tumor microenvironment are maintained in the same way as in humans. The important thing is that several carcinogenesis models complement one another. 
Finally, the integration of this information from carcinogenesis models and human GWAS information will facilitate the identification of human cancer susceptibility genes and polymorphisms, which will enable us to predict cancer risk and develop strategies for targeted therapy

Author Contributions: K.O. wrote the manuscript. M.S. and E.I. collected data from the literature. Y.W. revised the manuscript. All authors have read and agreed to the published version of the manuscript.

Funding: These works were supported, in part, by JSPS Kakenhi (19K07494, 15K06817, 25860303).

Institutional Review Board Statement: This study was conducted according to the guidelines of the Care and Use of Laboratory Animals of the Ministry of Education, Culture, Sports, Science, and Technology of Japan, and approved by the Ethics Committee of Chiba Cancer Center (protocol code: 19-13, approved on 24 July 2019).

Informed Consent Statement: Not applicable.

Data Availability Statement: The data presented in this study are available on request from the corresponding author.

Acknowledgments: The authors would like to acknowledge Ryo Kominami for his suggestions on his previous study on radiation-induced thymic lymphomas.

Conflicts of Interest: The authors declare no conflict of interest.

\section{References}

1. Stadler, Z.K.; Thom, P.; Robson, M.E.; Weitzel, J.N.; Kauff, N.D.; Hurley, K.E.; Devlin, V.; Gold, B.; Klein, R.J.; Offit, K. Genomewide association studies of cancer. J. Clin. Oncol. 2010, 28, 4255-4267. [CrossRef]

2. Pérez-Losada, J.; Castellanos-Martín, A.; Mao, J.H. Cancer evolution and individual susceptibility. Integr. Biol. 2011, 3, $316-328$. [CrossRef]

3. Dietrich, W.F.; Lander, E.S.; Smith, J.S.; Moser, A.R.; Gould, K.A.; Luongo, C.; Borenstein, N.; Dove, W. Genetic identification of Mom-1, a major modifier locus affecting Min-induced intestinal neoplasia in the mouse. Cell 1993, 75, 631-639. [CrossRef]

4. Fijneman, R.J.; de Vries, S.S.; Jansen, R.C.; Demant, P. Complex interactions of new quantitative trait loci, Sluc1, Sluc2, Sluc3, and Sluc4, that influence the susceptibility to lung cancer in the mouse. Nat. Genet. 1996, 14, 465-467. [CrossRef] [PubMed]

5. Ruivenkamp, C.A.L.; van Wezel, T.; Zanon, C.; Stassen, A.P.M.; Vlcek, C.; Csikós, T.; Klous, A.M.; Tripodis, N.; Perrakis, A.; Boerrigter, L.; et al. Ptprj is a candidate for the mouse colon-cancer susceptibility locus Scc1 and is frequently deleted in human cancers. Nat. genet. 2002, 31, 295-300. [CrossRef]

6. Demant, P. Cancer susceptibility in the mouse: Genetics, biology and implications for human cancer. Nat. Rev. Genet. 2003, 4, 721-734. [CrossRef]

7. Dragani, T.A. 10 years of mouse cancer modifier loci: Human relevance. Cancer Res. 2003, 63, 3011-3018.

8. Mao, J.-H.; Balmain, A. Genomic approaches to identification of tumour-susceptibility genes using mouse models. Curr. Opin. Genet. Dev. 2003, 13, 14-19. [CrossRef]

9. Nagase, H.; Bryson, S.; Cordell, H.; Kemp, C.J.; Fee, F.; Balmain, A. Distinct genetic loci control development of benign and malignant skin tumours in mice. Nat. Genet. 1995, 10, 424-429. [CrossRef]

10. To, M.D.; Perez-Losada, J.; Mao, J.-H.; Hsu, J.; Jacks, T.; Balmain, A. A functional switch from lung cancer resistance to susceptibility at the Pas1 locus in Kras2LA2 mice. Nat. Genet. 2006, 38, 926-930. [CrossRef]

11. Santos, J.; Montagutelli, X.; Acevedo, A.; López, P.; Vaquero, C.; Fernández, M.; Arnau, M.-R.; Szatanik, M.; Salido, E.; Guénet, J.-L.; et al. A new locus for resistance to gamma-radiation-induced thymic lymphoma identified using inter-specific consomic and inter-specific recombinant congenic strains of mice. Oncogene 2002, 21, 6680-6683. [CrossRef] [PubMed]

12. Ewart-Toland, A.; Briassouli, P.; de Koning, J.P.; Mao, J.-H.; Yuan, J.; Chan, F.; MacCarthy-Morrogh, L.; Ponder, B.A.J.; Nagase, H.; Burn, J.; et al. Identification of Stk6/STK15 as a candidate low-penetrance tumor-susceptibility gene in mouse and human. Nat. Genet. 2003, 34, 403-412. [CrossRef]

13. Peissel, B.; Zaffaroni, D.; Zanesi, N.; Zedda, I.; Manenti, G.; Rebessi, S.; Pazzaglia, S.; Doria, G.; Covelli, V.; Dragani, T.A.; et al. Linkage disequilibrium and haplotype mapping of a skin cancer susceptibility locus in outbred mice. Mamm. Genome 2000, 11, 979-981. [CrossRef]

14. Wakabayashi, Y.; Mao, J.-H.; Brown, K.; Girardi, M.; Balmain, A. Promotion of Hras-induced squamous carcinomas by a polymorphic variant of the Patched gene in FVB mouse. Nature 2007, 445, 761-765. [CrossRef] [PubMed]

15. Angel, J.M.; Beltrán, L.; Minda, K.; Rupp, T.; DiGiovanni, J. Association of a murine chromosome 9 locus (Psl1) with susceptibility to mouse skin tumor promotion by 12-O-tetradecanoylphorbol-13-acetate. Mol. Carcinog. 1997, 20, 162-167. [CrossRef] 
16. Angel, J.M.; Caballero, M.; DiGiovanni, J. Identification of novel genetic loci contributing to 12-O-tetradecanoylphorbol-13-acetate skin tumor promotion susceptibility in DBA/2 and C57BL/ 6 mice. Cancer Res. 2003, 63, 2747-2751.

17. Fujiwara, K.; Igarashi, J.; Irahara, N.; Kimura, M.; Nagase, H. New chemically induced skin tumour susceptibility loci identified in a mouse backcross between FVB and dominant resistant PWK. BMC Genet. 2007, 8, 39. [CrossRef]

18. Fujiwara, K.; Wie, B.; Elliott, R.; Nagase, H. New outbred colony derived from Mus musculus castaneus to identify skin tumor susceptibility loci. Mol. Carcinog. 2010, 49, 653-661. [CrossRef]

19. Moriwaki, K.; Shiroishi, T.; Yonekawa, H. Genetics in Wild Mice; Japan Scientific Societies Press: Tokyo, Japan; Karger: Basel, Switzerland, 1994.

20. Yonekawa, H.; Moriwaki, K.; Gotoh, O.; Miyashita, N.; Matsushima, Y.; Shi, L.M.; Cho, W.S.; Zhen, X.L.; Tagashira, Y. Hybrid origin of Japanese mice "Mus musculus molossinus": Evidence from restriction analysis of mitochondrial DNA. Mol. Biol. Evol. 1988, 5, 63-78.

21. Takada, T.; Ebata, T.; Noguchi, H.; Keane, T.M.; Adams, D.J.; Narita, T.; Shin-I., T.; Fujisawa, H.; Toyoda, A.; Abe, K.; et al. The ancestor of extant Japanese fancy mice contributed to the mosaic genomes of classical inbred strains. Genome Res. 1988, 23, 1329-1338. [CrossRef]

22. Moriwaki, K.; Miyashita, N.; Mita, A.; Gotoh, H.; Tsuchiya, K.; Kato, H.; Mekada, K.; Noro, C.; Oota, S.; Yoshiki, A.; et al. Unique inbred strain MSM/Ms established from the Japanese wild mouse. Exp. Anim. 2009, 58, 123-134. [CrossRef]

23. Kikkawa, Y.; Miura, I.; Takahama, S.; Wakana, S.; Yamazaki, Y.; Moriwaki, K.; Shiroishi, T.; Yonekawa, H. Microsatellite database for MSM/Ms and JF1/Ms, molossinus-derived inbred strains. Mamm. Genome 2001, 12, 750-752. [CrossRef] [PubMed]

24. Abe, K.; Noguchi, H.; Tagawa, K.; Yuzuriha, M.; Toyoda, A.; Kojima, T.; Ezawa, K.; Saitou, N.; Hattori, M.; Sakaki, Y.; et al. Contribution of Asian mouse subspecies Mus musculus molossinus to genomic constitution of strain C57BL/6J, as defined by BAC-end sequence-SNP analysis. Genome Res. 2004, 14, 2439-2447. [CrossRef]

25. Kobayashi, M.; Ohno, T.; Tsuchiya, T.; Horio, F. Characterization of diabetes-related traits in MSM and JF1 mice on high-fat diet. J. Nutr. Biochem. 2004, 15, 614-621. [CrossRef]

26. Koide, T.; Moriwaki, K.; Ikeda, K.; Niki, H.; Shiroishi, T. Multiphenotype behavioral characterization of inbred strains derived from wild stocks of Mus musculus. Mamm. Genome 2000, 11, 664-670. [CrossRef]

27. Nemoto, M.; Morita, Y.; Mishima, Y.; Takahashi, S.; Nomura, T.; Ushiki, T.; Shiroishi, T.; Kikkawa, Y.; Yonekawa, H.; Kominami, R. Ahl3, a third locus on mouse chromosome 17 affecting age-related hearing loss. Biochem. Biophys. Res. Commun. 2004, 324, 1283-1288. [CrossRef]

28. Miyasaka, Y.; Suzuki, S.; Ohshiba, Y.; Watanabe, K.; Sagara, Y.; Yasuda, S.-P.; Matsuoka, K.; Shitara, H.; Yonekawa, H.; Kominami, R.; et al. Compound heterozygosity of the functionally null Cdh23(v-ngt) and hypomorphic Cdh23(ahl) alleles leads to early-onset progressive hearing loss in mice. Exp. Anim. 2013, 62, 333-346. [CrossRef]

29. Nakanishi, M.; Tazawa, H.; Tsuchiya, N.; Sugimura, T.; Tanaka, T.; Nakagama, H. Mouse strain differences in inflammatory responses of colonic mucosa induced by dextran sulfate sodium cause differential susceptibility to PhIP-induced large bowel carcinogenesis. Cancer Sci. 2007, 98, 1157-1163. [CrossRef]

30. Okamoto, M.; Yonekawa, H. Intestinal tumorigenesis in Min mice is enhanced by X-irradiation in an age-dependent manner. J. Radiat. Res. 2005, 46, 83-91. [CrossRef]

31. Pataer, A.; Kamoto, T.; Lu, L.M.; Yamada, Y.; Hiai, H. Two dominant host resistance genes to pre-B lymphoma in wild-derived inbred mouse strain MSM/Ms. Cancer Res. 1996, 56, 3716-3720.

32. Okumoto, M.; Mori, N.; Miyashita, N.; Moriwaki, K.; Imai, S.; Haga, S.; Hiroishi, S.; Takamori, Y.; Esaki, K. Radiation-induced lymphomas in MSM, (BALB/cHeA x MSM) F1 and (BALB/cHeA x STS/A) F1 hybrid mice. Exp. Anim. 1995, 44, 43-48. [CrossRef]

33. Saito, Y.; Ochiai, Y.; Kodama, Y.; Tamura, Y.; Togashi, T.; Kosugi-Okano, H.; Miyazawa, T.; Wakabayashi, Y.; Hatakeyama, K.; Wakana, S.; et al. Genetic loci controlling susceptibility to gamma-ray-induced thymic lymphoma. Oncogene 2001, 20, 5243-5247. [CrossRef]

34. Miyasaka, K.; Ohtake, K.; Nomura, K.; Kanda, H.; Kominami, R.; Miyashita, N.; Kitagawa, T. Frequent loss of heterozygosity on chromosome 4 in diethylnitrosamine-induced C3H/MSM mouse hepatocellular carcinomas in culture. Mol. Carcinog. 1995, 13, 37-43. [CrossRef]

35. Masui, T.; Tezuka, N.; Nakanishi, H.; Inada, K.-I.; Miyashita, N.; Tatematsu, M. Induction of invasive squamous cell carcinomas in the forestomach of (C3H x MSM)F1, MSM, and C3H mice by $\mathrm{N}$-methyl-N-nitrosourea and mutational analysis of the H-ras and p53 genes. Cancer Lett. 1997, 111, 97-104. [CrossRef]

36. Okumura, K.; Sato, M.; Saito, M.; Miura, I.; Wakana, S.; Mao, J.H.; Miyasaka, Y.; Kominami, R.; Wakabayashi, Y. Independent genetic control of early and late stages of chemically induced skin tumors in a cross of a Japanese wild-derived inbred mouse strain, MSM/Ms. Carcinogenesis 2012, 33, 2260-2268. [CrossRef]

37. Araki, K.; Takeda, N.; Yoshiki, A.; Obata, Y.; Nakagata, N.; Shiroishi, T.; Moriwaki, K.; Yamamura, K. Establishment of germlinecompetent embryonic stem cell lines from the MSM/Ms strain. Mamm. Genome 2009, 20, 14-20. [CrossRef]

38. Hemann, M.T.; Greider, C.W. Wild-derived inbred mouse strains have short telomeres. Nucleic Acids Res. 2000, $28,4474-4478$. [CrossRef]

39. Zhu, L.; Hathcock, K.S.; Hande, P.; Lansdorp, P.M.; Seldin, M.F.; Hodes, R.J. Telomere length regulation in mice is linked to a novel chromosome locus. Proc. Natl. Acad. Sci. USA 1998, 95, 8648-8653. [CrossRef] 
40. Ullrich, R.L.; Bowles, N.D.; Satterfield, L.C.; Davis, C.M. Strain-dependent susceptibility to radiation-induce mammary cancer is a result of differences in epithelial cell sensitivity to transformation. Radiat. Res. 1996, 146, 353-355. [CrossRef]

41. Li, Y.R.; Halliwill, K.D.; Adams, C.J.; Iyer, V.; Riva, L.; Mamunur, R.; Jen, K.Y.; Del Rosario, R.; Fredlund, E.; Hirst, G.; et al. Mutational signatures in tumours induced by high and low energy radiation in Trp53 deficient mice. Nat. Commun. 2020, 11, 394.

42. Tamura, Y.; Maruyama, M.; Mishima, Y.; Fujisawa, H.; Obata, M.; Kodama, Y.; Yoshikai, Y.; Aoyagi, Y.; Niwa, O.; Schaffner, W.; et al. Predisposition to mouse thymic lymphomas in response to ionizing radiation depends on variant alleles encoding metal-responsive transcription factor-1 (Mtf-1). Oncogene 2005, 24, 399-406. [CrossRef]

43. Kodama, Y.; Yoshikai, Y.; Tamura, Y.; Wakana, S.; Takagi, R.; Niwa, O.; Kominami, R. The D5Mit7 locus on mouse chromosome 5 provides resistance to gamma-ray-induced but not $\mathrm{N}$-methyl-N-nitrosourea-induced thymic lymphomas. Carcinogenesis 2004, 25, 143-148. [CrossRef]

44. Ochiai, Y.; Tamura, Y.; Saito, Y.; Matsuki, A.; Wakabayashi, Y.; Aizawa, Y.; Niwa, O.; Kominami, R. Mapping of genetic modifiers of thymic lymphoma development in p53-knockout mice. Oncogene 2003, 22, 1098-1102. [CrossRef]

45. Matsumoto, Y.; Kosugi, S.; Shinbo, T.; Chou, D.; Ohashi, M.; Wakabayashi, Y.; Sakai, K.; Okumoto, M.; Mori, N.; Aizawa, S.; et al. Allelic loss analysis of gamma-ray-induced mouse thymic lymphomas: Two candidate tumor suppressor gene loci on chromosomes 12 and 16. Oncogene 1998, 16, 2747-2754. [CrossRef]

46. Shinbo, T.; Matsuki, A.; Matsumoto, Y.; Kosugi, S.; Takahashi, Y.; Niwa, O.; Kominami, R. Allelic loss mapping and physical delineation of a region harboring a putative thymic lymphoma suppressor gene on mouse chromosome 12. Oncogene 1999, 18, 4131-4136. [CrossRef]

47. Wakabayashi, Y.; Inoue, J.; Takahashi, Y.; Matsuki, A.; Kosugi-Okano, H.; Shinbo, T.; Mishima, Y.; Niwa, O.; Kominami, R. Homozygous deletions and point mutations of the Rit1/Bcl11b gene in gamma-ray induced mouse thymic lymphomas. Biochem. Biophys. Res. Commun. 2003, 301, 598-603. [CrossRef]

48. Wakabayashi, Y.; Watanabe, H.; Inoue, J.; Takeda, N.; Sakata, J.; Mishima, Y.; Hitomi, J.; Yamamoto, T.; Utsuyama, M.; Niwa, O.; et al. $\mathrm{Bcl11b}$ is required for differentiation and survival of alphabeta T lymphocytes. Nat. Immunol. 2003, 4, 533-539. [CrossRef] [PubMed]

49. Kamimura, K.; Ohi, H.; Kubota, T.; Okazuka, K.; Yoshikai, Y.; Wakabayashi, Y.; Aoyagi, Y.; Mishima, Y.; Kominami, R. Haploinsufficiency of Bcl11b for suppression of lymphomagenesis and thymocyte development. Biochem. Biophys. Res. Commun. 2007, 355, 538-542. [CrossRef]

50. Okano, H.; Saito, Y.; Miyazawa, T.; Shinbo, T.; Chou, D.; Kosugi, S.; Takahashi, Y.; Odani, S.; Niwa, O.; Kominami, R. Homozygous deletions and point mutations of the Ikaros gene in gamma-ray-induced mouse thymic lymphomas. Oncogene 1999, 18, 6677-6683. [CrossRef]

51. Xu, H.; Wakabayashi, Y.; Okano, H.; Saito, Y.; Miyazawa, T.; Kominami, R. Genetic mapping and allelic loss analysis in mouse thymic lymphomas of Helios and Aiolos belonging to the Ikaros gene family. Jpn. J. Cancer Res. 2001, 92, 36-41. [CrossRef]

52. Abel, E.L.; Angel, J.M.; Kiguchi, K.; DiGiovanni, J. Multi-stage chemical carcinogenesis in mouse skin: Fundamentals and applications. Nat. Protoc. 2009, 4, 1350-1362. [CrossRef]

53. Okumura, K.; Saito, M.; Isogai, E.; Miura, I.; Wakana, S.; Kominami, R.; Wakabayashi, Y. Congenic mapping and allele-specific alteration analysis of Stmm1 locus conferring resistance to early-stage chemically induced skin papillomas. PLoS ONE 2014, 9, e97201. [CrossRef]

54. Okumura, K.; Saito, M.; Yoshizawa, Y.; Munakata, H.; Isogai, E.; Miura, I.; Wakana, S.; Yamaguchi, M.; Shitara, H.; Taya, C.; et al. The parathyroid hormone regulates skin tumour susceptibility in mice. Sci. Rep. 2017, 7, 11208. [CrossRef] [PubMed]

55. Safer, J.D.; Ray, S.; Holick, M.F. A topical parathyroid hormone/parathyroid hormone-related peptide receptor antagonist stimulates hair growth in mice. Endocrinology 2007, 148, 1167-1170. [CrossRef]

56. Okumura, K.; Saito, M.; Yoshizawa, Y.; Ito, Y.; Isogai, E.; Araki, K.; Wakabayashi, Y. Pak1 maintains epidermal stem cells by regulating Langerhans cells and is required for skin carcinogenesis. Oncogene 2020, 39, 4756-4769. [CrossRef] [PubMed]

57. Saito, M.; Okumura, K.; Miura, I.; Wakana, S.; Kominami, R.; Wakabayashi, Y. Identification of Stmm3 locus conferring resistance to late-stage chemically induced skin papillomas on mouse chromosome 4 by congenic mapping and allele-specific alteration analysis. Exp. Anim. 2014, 63, 339-348. [CrossRef] [PubMed]

58. Kamijo, T.; Zindy, F.; Roussel, M.F.; Quelle, D.E.; Downing, J.R.; Ashmun, R.A.; Grosveld, G.; Sherr, C.J. Tumor suppression at the mouse INK4a locus mediated by the alternative reading frame product p19ARF. Cell 1997, 91, 649-659. [CrossRef]

59. Kamijo, T.; Weber, J.D.; Zambetti, G.; Zindy, F.; Roussel, M.F.; Sherr, C.J. Functional and physical interactions of the ARF tumor suppressor with p53 and Mdm2. Proc. Natl. Acad. Sci. USA 1998, 95, 8292-8297. [CrossRef] [PubMed]

60. Saito, M.; Okumura, K.; Isogai, E.; Araki, K.; Tanikawa, C.; Matsuda, K.; Kamijo, T.; Kominami, R.; Wakabayashi, Y. A Polymorphic Variant in p19Arf Confers Resistance to Chemically Induced Skin Tumors by Activating the p53 Pathway. J. Investig. Derm. 2019, 139, 1459-1469. [CrossRef]

61. Takada, T.; Shiroishi, T. Complex Quantitative Traits Cracked by the Mouse Inter-Subspecific Consomic Strains. Exp. Anim. 2012, 61,375-388. [CrossRef] 